DOI: https://doi.org/10.33103/uot.ijccce.20.2.8

\title{
Performance Evaluation of Fiber Bragg Grating Strain Sensor Integrating in WDM Communication System
}

\author{
Mohammed Ali Yaseen ${ }^{1}$, A. K. Abass ${ }^{2}$, Sinan Majid ${ }^{3}$ \\ ${ }^{1,3}$ Electrical Engineering Department, University of Technology-Iraq, Baghdad, Iraq \\ ${ }^{2}$ Laser and Optoelectronics Engineering Department, University of Technology-Iraq, Baghdad, Iraq \\ 140042@uotechnology.edu.iq
}

\begin{abstract}
In this paper, a fiber Bragg grating (FBG) strain sensor is simulated utilizing OptiGrating software. Then the proposed sensor is integrated into the wavelength division multiplexing (WDM) communication system via OptiSystem software in order to evaluate its performance as a strain sensor. The proposed WDM system has 4-channels with NRZ modulation format and $100 \mathrm{GHz}$ frequency spacing. According to the results, the degradation in the receiving signal reaching the limitation value (6 for $Q$-factor and $10 E-9$ for BER) at applied strain ranging from $170 \mu \varepsilon-t o-180 \mu \varepsilon$.
\end{abstract}

Index Terms-BER, Fiber Bragg strain sensor, Q-Factor, WDM communication system.

\section{INTRODUCTION}

WDM is one of the most popular techniques used to increase the number of channels in fiber optic communication. WDM uses multiple channels that have different wavelengths that can be transmitted through the same fiber [1]. On the other hand, the FBGs are used in a wide range of sensing applications such as thermal, pressure and strain sensor [2], as well as in fiber optic communication systems as dispersion compensator [3], optical filter [4] and add/drop frequency in a WDM system [1]. Thus, its invention considered a milestone in the optoelectronics field. In addition, Yi-Lin $\mathrm{Yu}$ et. al, incorporated an FBG into the WDM system as a strain sensor to monitor unusual behaviors on that system, and give an indication to an optical switch to switched from fiber-optic to free-space optical system [5]. Furthermore, the simulation programs offer low cost and high design tolerances in practical, as well as decrease the computational time required to solve the theoretical complex equations. In this context, the abilities of both OptiSystem and OptiGrating simulation programs in the optoelectronics field have been demonstrated for decades and up to presents [6]-[8]. In addition, the combination between these two programs produces a perfect optical architecture as well as more reliability assembly. This incorporation was proposed in several published works such as design FBG dispersion compensator, strain/temperature sensor, and tunable filter via OptiGarting and integrating these architectures in OptiSystem software [9]-[13]

To the best of our knowledge, there is no published work incorporating the FBG strain sensor in the WDM communication system as an integrated assembly simulated between OptiGrating and OptiSystem software. In this work, this assembly is demonstrated and investigated under different strain conditions.

\section{EXPERIMENT SETUP}

This section includes three parts, namely, FBG strain sensor design, WDM communication system design and incorporating the FBG sensor into the WDM system. 


\section{A. FBGs Strain Sensors Design}

In this subsection, the OptiGrating software is used to design four FBGs strain sensors at center frequencies, namely, $1553.329 \mathrm{~nm}, 1552.524 \mathrm{~nm}, 1551.720 \mathrm{~nm}$ and $1550.918 \mathrm{~nm}$ in order to monitor the effect of the applied strain on the WDM system, the characteristics of the simulated FBGs sensors are depicted in Table-1.

TABLE-1: THE CHARACTERISTICS OF THE PROPOSED FBGS

\begin{tabular}{cc}
\hline Bragg wavelength, $\boldsymbol{\lambda}_{\mathbf{B}} \mathbf{n m}$ & $1553.329,1552.524,1551.720$ and 1550.918 \\
Grating length, $\mathbf{L}$ & $7 \mathrm{~mm}$ \\
Index modulation & 0.0005 \\
Grating period, $\boldsymbol{\Lambda}$ & $0.534 \mu \mathrm{m}$ \\
\hline
\end{tabular}

\section{B. WDM Communication System Design}

In this work, a 4-channels WDM system is simulated via OptiSystem software. The input signal is achieved from array laser diodes with wavelength ranging from $1553.329 \mathrm{~nm}$ to $1550.918 \mathrm{~nm}$ with a step of $0.8 \mathrm{~nm}$, frequency linewidth of $10 \mathrm{MHz}$ and output power of $10 \mathrm{dBm}$. Two erbium-doped fiber amplifiers are used in order to compensate the transmission losses with gain level and noise figure of $20 \mathrm{~dB}$ and $6 \mathrm{~dB}$, respectively. The chromatic dispersion is compensated via $10 \mathrm{~km}$ of dispersion compensating fiber (DCF), with negative dispersion of $-85 \mathrm{ps} / \mathrm{nm} / \mathrm{km}$.

\section{Incorporating the FBG sensor into the WDM system}

In this section, the proposed FBG strain sensor is incorporated within the designed 4 channels WDM system as illustrated in Figure 1.

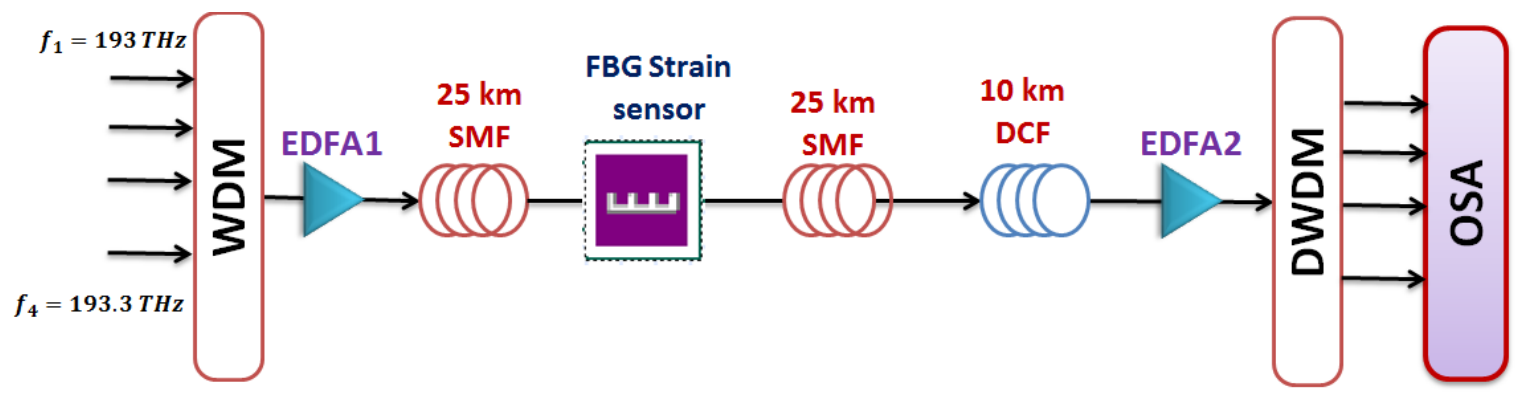

FIGURE 1: STRAIN SENSOR BASED ON FBG INCORPORATING WITH 4 CHANNELS 100 GHz WDM COMMUNICATION SYSTEM.

\section{RESULTS AND DISCUSSION}

\section{A. Characteristics of the FBG Strain Sensor}

The performance of the proposed 4-FBGs strain sensors is investigated and evaluated under different strain conditions. The transmissivity and reflectivity at 0 microstrain are illustrated in Figure 2 ( $\mathrm{a}, \mathrm{b}, \mathrm{c}$, and $\mathrm{d}$ ). Based on the design parameters adopted in OptiGrating software, the peaks reflected power was at $1553.329 \mathrm{~nm}, 1552.524 \mathrm{~nm}$, $1551.720 \mathrm{~nm}$, and $1550.918 \mathrm{~nm}$.

Furthermore, the reflectivity of the FBG sensors at several micro strains ranging from 0 -to- 300 is investigated as depicted in Figure 3. According to the results, the center reflected wavelength for whole sensors is shifted about $0.37 \mathrm{~nm}$ as the strain increased from 0 -to- $300 \mu$ strain. This shifting is due to change in elasto-optic effect and elasticity of the fiber which is caused by changing ineffective refractive index (neff) and the grating period 
$(\Lambda)$ which is affected on Bragg wavelength $(\lambda B)[4,13]$. The analyzed data from Figure 3 is investigated in order to illustrate the shifting in center wavelength as depicted in Figure 4.
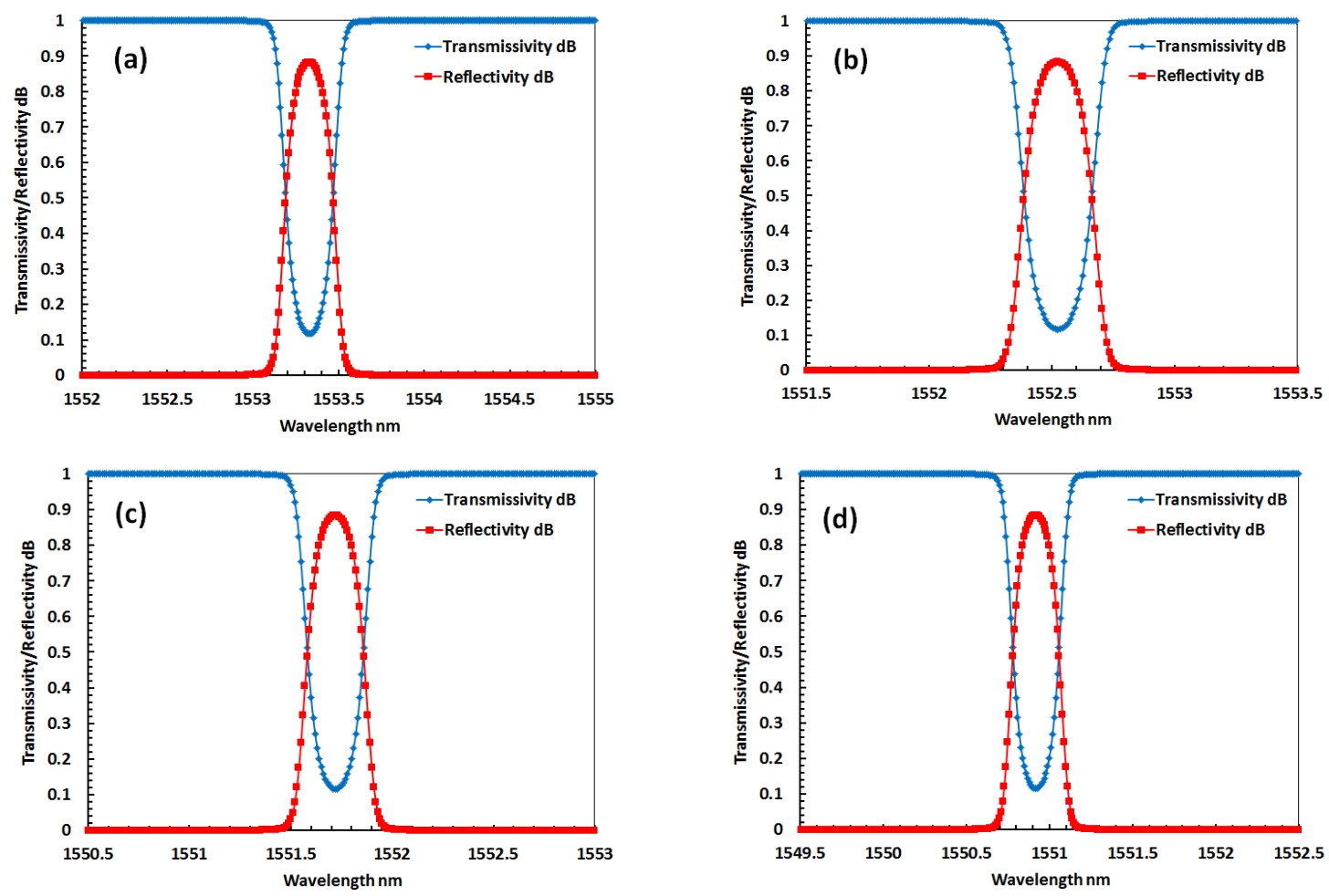

FIGURE 2: TRANSMITTIVITY AND REFLECTIVITY OF THE PROPOSED FBGS STRAIN SENSORS AT 0 STRAIN: (A) $\lambda \mathrm{B}=1553.329 \mathrm{NM}$, (B) $\lambda \mathrm{B}=1552.524 \mathrm{NM}$, (C) $\lambda \mathrm{B}=1551.720 \mathrm{NM}$ AND (D) $\lambda \mathrm{B}=1550.918 \mathrm{NM}$.
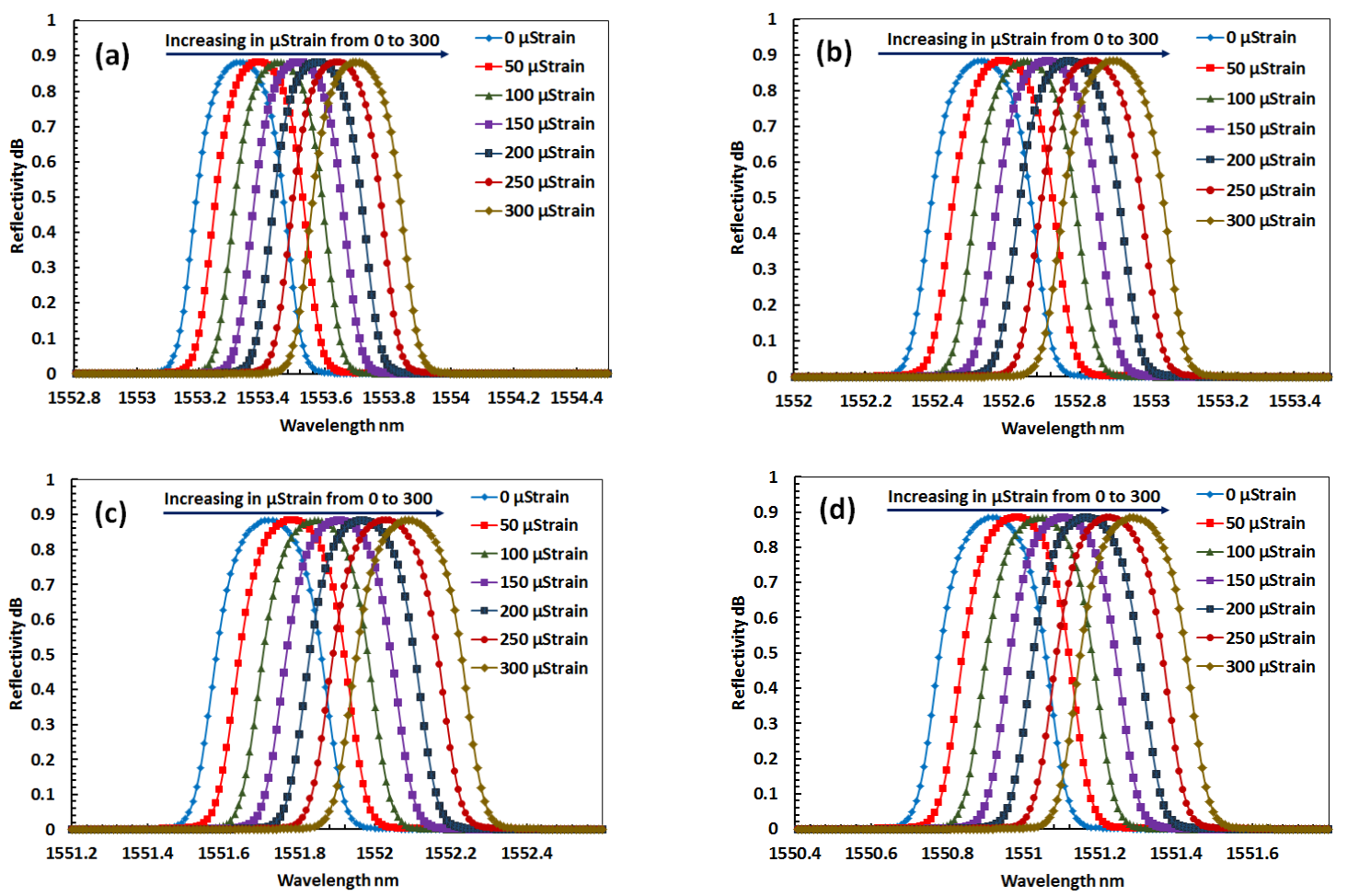

FIGURE 3: THE REFLECTIVITY OF THE PROPOSED FBG SENSOR UNDER DIFFERENT STRAIN VALUES FROM 0 -TO-300 $\mu$ STRAIN: (A) $\lambda \mathrm{B}=1553.329 \mathrm{NM},(\mathrm{B}) \lambda \mathrm{B}=1552.524 \mathrm{NM}$, (C) $\lambda \mathrm{B}=1551.720 \mathrm{NM}$ AND (D) $\lambda \mathrm{B}=1550.918 \mathrm{NM}$. 


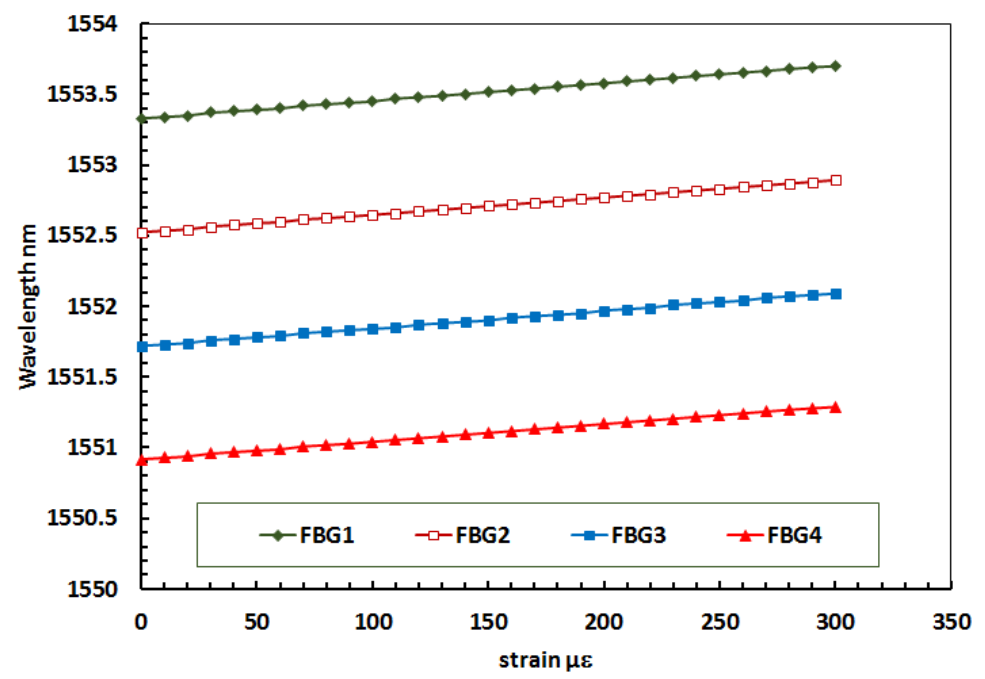

FIGURE 4: THE ANALYZED DATA FROM FIGURE 3 SHOWING THE APPLIED STRAIN EFFECT ON SHIFTING IN FIBER BRAGG GRATING WAVELENGTH.

\section{B. Characteristics of WDM communication system}

In this subsection, the performance of the proposed WDM system is investigated and evaluated under different strain conditions. Both of the BER and Q-Factor is adopted in this evaluation as depicted in Figure 5. The measured strain values were limited within approximately 6 and 10-9 for Q-factor and BER, respectively [14]. According to the results, as the applied strain increased the Q-factor reduced and the BER increased.
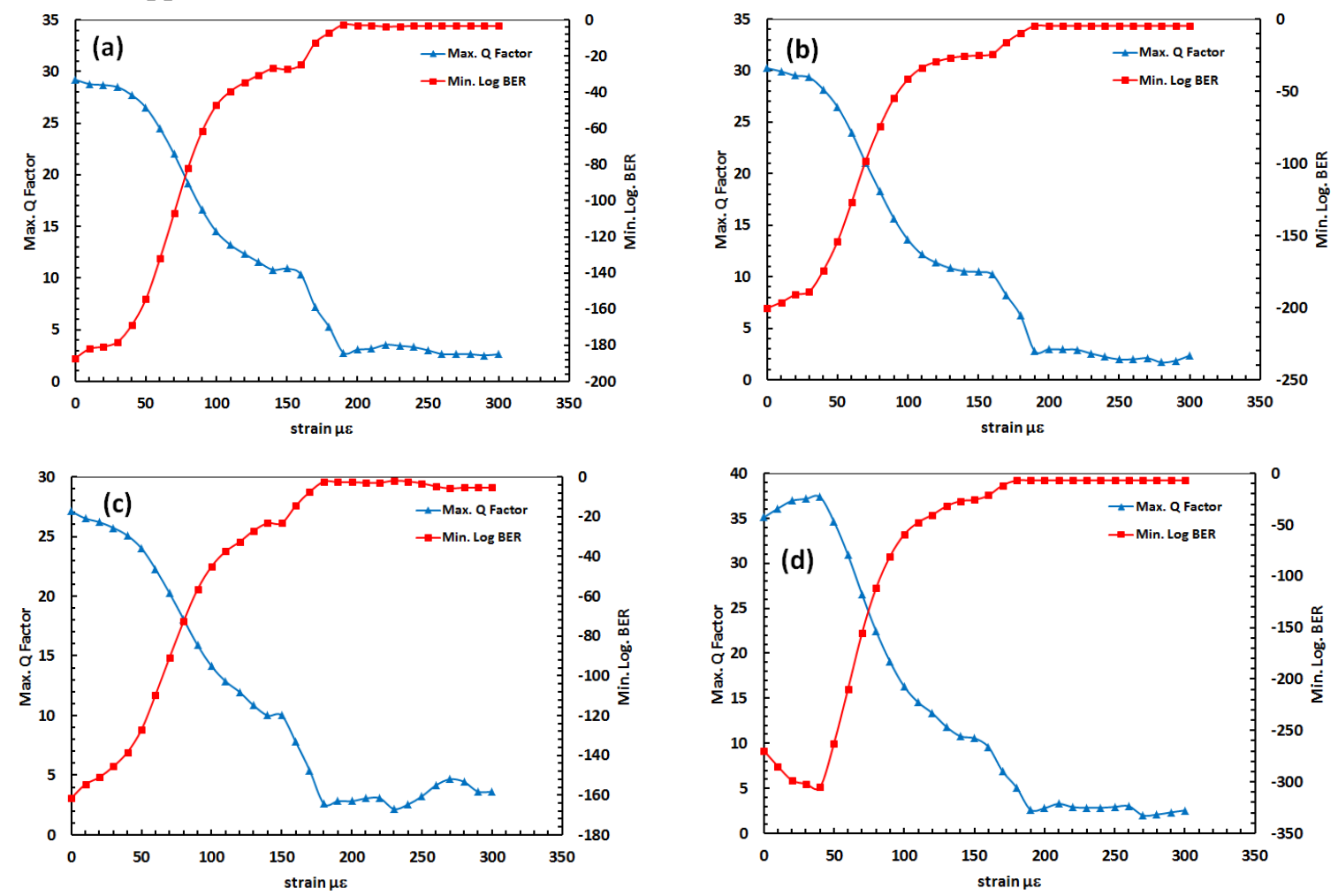

FIGURE 5: EFFECT OF APPLIED STRAIN ON BOTH OF THE Q-FACTOR and BER FOR: (a) $\lambda_{\mathrm{B}}=1553.329 \mathrm{~nm}$, (b) $\lambda_{\mathrm{B}}=1552.524 \mathrm{~nm}$, (c) $\lambda_{\mathrm{B}}=1551.720 \mathrm{~nm}$ and (d) $\lambda_{\mathrm{B}}=1550.918 \mathrm{~nm}$.

This behavior indicates that the applied strain caused a redshift in the input signal wavelength as a result distorted the information in the receiving terminal of the WDM 
system. Moreover, for whole strain sensors the degradation in the receiving signal reaching the limitation value (6 for Q-factor and $10 \mathrm{E}-9$ for BER) at applied strain ranging from 170 $\mu \varepsilon-$ to $-180 \mu \varepsilon$.

\section{CONCLUSION}

The combination between OptiSystem and OptiGrating software was simulated and designed an integrated assembly includes $100 \mathrm{GHz}$ WDM systems and FBG strain sensor. This work can be recommended as a communication system using the infrastructure of cities, especially via bridges, as it consists of a strain sensor. In addition, in the next step, we will combine a free-space optical (FSO) system to work as an emergency communication system for the fiber optic link. According to the results, the degradation in the receiving signal reaching the limitation value (6 for Q-factor and 10-9 for BER) at applied strain ranging from $170 \mu \varepsilon-$ to $-180 \mu \varepsilon$.

\section{REFERENCES}

[1] J. Li, J. Wang, W. Jiang, X. Dong, L. Pei, and S. Jian, “Tunable erbium doped fiber ring laser using fiber Bragg gratingassisted add-drop filter,” Opt. Commun., vol. 282, no. 15, pp. 3136-3139, 2009.

[2] Y. Yang, C. Hong, Z. Ahmed Abro, L. Wang, and Z. Yifan, "A new Fiber Bragg Grating sensor based circumferential strain sensor fabricated using 3D printing method," Sensors Actuators, A Phys., vol. 295, pp. 663-670, 2019.

[3] Z. Tan et al., "Transmission system over $3000 \mathrm{~km}$ with dispersion compensated by chirped fiber Bragg gratings," Optik (Stuttg)., vol. 120, no. 1, pp. 9-13, 2009.

[4] A. Z. Mohammed, A. K. Abass, S. K. Ibrahim, and W. Y. Nassir, "Theoretical Analysis of Fiber Bragg Grating Tunable Filter Utilizing Tensile / Compression Technique,” Diyala J. Eng. Sci., vol. 11, no. 2, pp. 55-59, 201.

[5] J. Li, J. Wang, W. Jiang, X. Dong, L. Pei, and S. Jian, "Tunable erbium doped fiber ring laser using fiber Bragg gratingassisted add-drop filter,” Opt. Commun., vol. 282, no. 15, pp. 3136-3139, 2009.

[6] Y. L. Yu, S. K. Liaw, H. H. Chou, H. Le-Minh, and Z. Ghassemlooy, "A Hybrid Optical Fiber and FSO System for Bidirectional Communications Used in Bridges,” IEEE Photonics J., vol. 7, no. 6, pp. 1-9, 2015.

[7] A. Sierra and S. V. Kartalopoulos, "Evaluation of two prevalent EPON networks using simulation methods," in Proceedings of the Advanced International Conference on Telecommunications and International Conference on Internet and Web Applications and Services, AICT/ICIW'06, 2006, vol. 2006, p. 48.

[8] M. H. Ali, F. Abdullah, M. Z. Jamaludin, M. H. Al-Mansoori, A. Ismail, and A. K. Abass, "Simulation and Experimental Validation of Gain Saturation in Raman Fiber Amplifier," in 3rd International Conference on Photonics , Penang, 2012, no. October, pp. 27-29.

[9] M. H. Ali, A. K. Abass, and S. A. Abd Al-Hussein, " 32 Channel $\times 40$ Gb/s WDM optical communication system utilizing different configurations of hybrid fiber amplifier,” Opt. Quantum Electron., vol. 51, no. 6, pp. 1-8, 2019.

[10] M. M. Elgaud, M. S. D. Zan, A. A. G. Abushagur, and A. A. A. Bakar, "Analysis of Independent Strain-Temperature Fiber Bragg Grating Sensing Technique Using OptiSystem and OptiGrating," in 6th International Conference on Photonics (ICP) Analysis, 2016, pp. 5-7.

[11] S. R. Tahhan, M. H. Ali, and A. K. Abass, "Characteristics of Dispersion Compensation for 32 Channels at $40 \mathrm{~Gb} / \mathrm{s}$ Under Different Techniques,” J. Opt. Commun., pp. 1-9, 2017.

[12] S. R. Tahhan, A. K. Abass, and M. H. Ali, "Characteristics of chirped fiber bragg grating dispersion compensator utilizing two apodization profiles," J. Commun., vol. 13, no. 3, pp. 108-113, 2018.

[13] A. Z. Mohammed, A. K. Abass, and S. K. Ibrahim, "Design and analysis of fiber Bragg grating tunable filter utilizing thermal technique," AIP Conf. Proc., vol. 2045, no. Egm, pp. 1-6, 2018.

[14] S. R. Tahhan, M. H. Ali, M. A. Z. Al-ogaidi, and A. K. Abass, "Impact of Apodization Profile on Performance of Fiber Bragg Grating Strain-Temperature Sensor,” J. Commun., vol. 14, no. 1, pp. 53-57, 2019.

[15] S. H. Alnajjar, M. H. Ali, and A. K. Abass, "Enhancing Performance of Hybrid FSO/Fiber Optic Communication Link Utilizing Multi-Channel Configuration,” J. Opt. Commun., pp. 3-8, 2019. 